\title{
Synchronizing developmental stages in Neotropical catfishes for application in germ cell transplantation
}

\author{
Dilberto Ribeiro Arashiro ${ }^{1,2}$, George Shigueki Yasui ${ }^{2,3}$, Leonardo Luiz Calado \\ ${ }^{3}$, Nivaldo Ferreira do Nascimento ${ }^{3,4}$, Matheus Pereira dos Santos ${ }^{4}$, Silvio Carlos Alves do Santos ${ }^{5}$, \\ Nycolas Levy-Pereira ${ }^{3,6}$, Paulo Sérgio Monzani ${ }^{3,6}$, Diógenes Henrique Siqueira-Silva ${ }^{7}$ \\ and José Augusto Senhorini ${ }^{2,3}$
}

Institute of Bioscience, São Paulo State University, Botucatu; Laboratory of Fish Biotechnology, National Center for Research Conservation of Continental Fish, Chico Mendes Institute of Biodiversity Conservation, Pirassununga; Aquaculture Center, São Paulo State University, Jaboticabal; AES Tietê, Promissão; Department of Veterinary Medicine - FZEA, Pirassununga; and UNIFESSPA, IESB, Marabá, Brazil

Date submitted: 11.08.2017. Date revised: 13.12.2017. Date accepted: 18.02 .2018

\section{Summary}

The aim of this study was to describe the effect of temperature on the fertilization, early developmental stages, and survival rate of two Neotropical catfishes Pimelodus maculatus and Pseudopimelodus mangurus. After fertilization, the eggs were incubated at $22^{\circ} \mathrm{C}, 26^{\circ} \mathrm{C}$, and $30^{\circ} \mathrm{C}$, which resulted in fertilization rates of $96.95 \pm 1.79 \%, 98.74 \pm 0.76 \%$, and $98.44 \pm 0.19 \%$ for P. maculatus and $96.10 \pm 1.58 \%, 98.00 \pm 0.63 \%$, and $94.60 \pm 2.09 \%$ for P. mangurus, respectively. For P. maculatus, hatching occurred after $22 \mathrm{~h} 30 \mathrm{~min}$ post-fertilization at $22^{\circ} \mathrm{C}, 16 \mathrm{~h} 30 \mathrm{~min}$ at $26^{\circ} \mathrm{C}$, and $11 \mathrm{~h} 20 \mathrm{~min}$ at $30^{\circ} \mathrm{C}$, and the hatching rates were $43.87 \pm 7,46 \%, 57.57 \pm 17.49 \%$, and $53.63 \pm 16.27 \%$, respectively. For P. mangurus, hatching occurred after $28 \mathrm{~h} 30 \mathrm{~min}$ post-fertilization at $22^{\circ} \mathrm{C}$ and $17 \mathrm{~h} 30 \mathrm{~min}$ at $26^{\circ} \mathrm{C}$ with respective hatching rates of $45.4 \pm 21.02 \%$ and $68.1 \pm 12.67 \%$. For this species, all embryos incubated at $30^{\circ} \mathrm{C}$ died before hatching. Additionally, for $P$. maculatus, the larvae from the lower $\left(22^{\circ} \mathrm{C}\right)$ and higher temperatures $\left(30^{\circ} \mathrm{C}\right)$ presented increased abnormality rates, as observed in the head, tail and yolk regions. The lowest abnormality rate was detected at $26^{\circ} \mathrm{C}$, which was considered the optimal incubation temperature for both species. The developed protocol enables the manipulation of embryonic development, which is important for the application of reproductive biotechniques, including chimerism and chromosome-set manipulation. The data obtained here are also important for the surrogate propagation of this species as P. mangurus was recently categorized as an endangered fish species.

Keywords: Incubation, PGC, Siluridae, Surrogate propagation, Temperature

\footnotetext{
${ }^{1}$ All correspondence to: Dilberto Ribeiro Arashiro. Laboratory of Fish Biotechnology, National Center for Research Conservation of Continental Fish, Chico Mendes Institute of Biodiversity Conservation, Rodovia Pref. Euberto Nemésio Pereira de Godoy, Pirassununga, Brazil. E-mail: dilbertoarashiro@hotmail.com

${ }^{2}$ Institute of Bioscience, São Paulo State University, Rua Prof. Doutor Antonio Celso Wagner Zanin, s/no., Botucatu, SP 18618-689, Brazil.

${ }^{3}$ Laboratory of Fish Biotechnology, National Center for Research Conservation of Continental Fish, Chico Mendes Institute of Biodiversity Conservation, Rodovia Pref. Euberto Nemésio Pereira de Godoy, Pirassununga, Brazil.
}

\footnotetext{
${ }^{4}$ Aquaculture Center, São Paulo State University, Via de Acesso Prof. Paulo Donato Castellane s/n, Jaboticabal, SP 14884-900, Brazil.

${ }^{5}$ AES Tietê, Br-153, Rod, 0 Km 139 Centro, Promissão, SP 16370-000, Brazil.

${ }^{6}$ Department of Veterinary Medicine - FZEA, Avenida Duque de Caxias Norte 225, Pirassununga, SP 13639-080 Brazil.

${ }^{7}$ UNIFESSPA - Federal University of South Southeast of Pará, Institute of Health Biological Studies (IESB), Folha 31, Quadra 7, Lote Especial, s/n - Nova Marabá, Marabá, PA 68507-590, Brazil.
} 


\section{Introduction}

The Neotropical region has one of the largest populations of ichthyofauna in the world, due to high diversity of hydrographic systems that results in a great variety of fish. Approximately 4399 freshwater species have been described and organized into two main orders. There have been 1847 Characiforms species and 2147 Siluriformes species identified with 57 Characiforms and 91 Siluriformes being considered endangered (Froese \& Pauly, 2015; Brasil, 2016) only in Brazil, which has one of the biggest ichthyofauna populations in the world. In Brazil, the Paraná River basin is an important basin showing a great variety of endemism (Galves et al., 2009) and endangered species, as is the case with Pseudopimelodus mangurus (Valenciennes, 1835). This species belongs to the Siluriformes order, and was recently included in the 'red list' of endangered species in the state of São Paulo (Bressan et al., 2009; São Paulo, 2014). This situation demands conservation strategies for this fish species.

Some reproductive biotechniques have been established for fish conservation, including surrogate propagation (Yasui et al., 2011) combined with sterile fish obtained by chromosome manipulation (Piferrer et al., 2009; do Nascimento et al., 2017). For the use of these techniques, prior knowledge about the stages of embryonic development is necessary (Fujimoto et al., 2006). The developmental stage can be influenced by several factors, and temperature is the main limiting factor in early development (Dos Santos et al., 2016). Temperature manipulation during early development is also a strategy for synchronizing embryonic development of different species. In germ cell transplantation techniques, the donor and host species must be synchronized at the same developmental stage, which can be achieved with controlled temperatures in both donor and host embryos.

Embryonic development in Neotropical fishes has not been fully investigated, especially in migratory fish species (Godinho \& Godinho, 2003). The aim of this study was to describe the developmental stages of two Siluriformes, to establish a protocol for germ cell transplantation. The donor species, the marbled catfish Pseudopimelodus mangurus, is a large bodied catfish ( $>8$ $\mathrm{kg}$ ) that was recently categorized as an endangered species (Bressan et al., 2009; São Paulo, 2014). For this species, domestication and reproduction are critical. As a host species, the spotted catfish Pimelodus maculatus (Lacépède, 1803) was selected as it is a small bodied catfish $(\sim 1 \mathrm{~kg})$ for which domestication and breeding procedures are well established under artificial conditions. In addition, P. maculatus can then be used as a model host for germ cells for other endangered Siluriformes.

\section{Materials and methods}

\section{Origin of broodstock and artificial fertilization}

All procedures were conducted at the Laboratory of Fish Biotechnology (Cepta/ICMBio, Pirassununga City, São Paulo State, Brazil).

Adult males and females of Pimelodus maculatus were collected in the Mogi Guassu river using a cast net (5 $\mathrm{cm}$ mesh) and, then, transferred to $1000 \mathrm{~m}^{2}$ earthen tanks. The fish were fed to satiation with a $6-\mathrm{mm}$ commercial fish pellet $(45 \%$ crude protein, $3800 \mathrm{kcal}$ $\mathrm{kg}^{-1}$ ) three times a week. These fish promptly accepted artificial feeding 5-10 days after collection. After a period of 3 to 6 months, the fish were selected for induced reproduction during the spawning season. Females are larger than males and present increased peritoneal areas, in addition to a reddish colour in the papillae area. Males were selected randomly based on the length reduced diameter of the body, in comparison with females. The females were anesthetized in clove oil $100 \mathrm{mg} \mathrm{l}^{-1}$ and induced with two doses of crude carp pituitary extract at $0.5 \mathrm{mg} \mathrm{kg}^{-1}$, followed by a second dose of $5 \mathrm{mg} \mathrm{kg}^{-1}$ after 165 hour-degrees. Males were induced to spermiation using a single dose of crude carp pituitary at $0.5 \mathrm{mg} \mathrm{kg}^{-1}$ at the same time as the second induction of the females. Reproduction induction was performed in 500 litre tanks with constant water flow. Gamete sampling was performed by hour-degrees methodology, which is performed by summing the water temperature $\left({ }^{\circ} \mathrm{C}\right)$ for each hour until spawning, resulting in 165 hourdegrees for both species. The oocytes were extruded in a glass bowl. Males were euthanized with the use of anaesthetic clove oil (100 $\left.\mathrm{mg} \mathrm{l}^{-1}\right)$ and sperm was collected by testicle maceration in a $15 \mathrm{ml}$ tube containing $3 \mathrm{ml}$ of calcium and magnesium-free Eagle's Minimum Essential Medium with the $\mathrm{pH}$ adjusted to 7.8 (E-MEM, Sigma, St. Louis, USA). The diluted sperm were added on the oocytes, and the gamete activation was achieved using $300 \mathrm{ml}$ of hatchery water.

The marbled catfish Pseudopimelodus mangurus adults were collected from the Mogi Guassu river during the spawning season using hook-and-line fishing with a baitfish (hook $>5 \mathrm{~cm}$ ). The fish were induced to spawn immediately after sampling using the same protocol described above for $P$. maculatus, but in doses of $0.6 \mathrm{mg} \mathrm{kg}^{-1}$ and $6 \mathrm{mg} \mathrm{kg}^{-1}$, and after induction, the broodstock was maintained in 8000 litre circular tanks with constant water flow. The females were selected by the same criteria described above, including increased redness of papilla and body volume. Males were selected based on the protuberant papillae and semen release after gently abdominal stripping. 
Gametes were collected using the same procedure described above. As the marbled catfish sperm is commonly contaminated with urine, the sperm was directly collected in a $15 \mathrm{ml}$ tube containing $5 \mathrm{ml}$ of calcium and magnesium-free Eagle's Minimum Essential Medium with the $\mathrm{pH}$ adjusted to 7.8 (E-MEM, Sigma, St. Louis, USA), used as immobilizing medium.

\section{Collection and embryonic development}

After fertilization, each spawning was divided into three batches at $22^{\circ} \mathrm{C}, 26^{\circ} \mathrm{C}$, and $30^{\circ} \mathrm{C}$. For each temperature, a small aliquot (30-80 embryos) was collected randomly and fixed in $2.5 \%$ glutaraldehyde in Dulbecco's phosphate-buffered saline (D-PBS) (Sigma \#D5773, St. Louis, USA). The samples were collected over the following time intervals: every $2 \mathrm{~min}$ postfertilization until $16 \mathrm{~min}$, every $5 \mathrm{~min}$ until $2 \mathrm{~h} 30 \mathrm{~min}$ post-fertilization; every $10 \mathrm{~min}$ until $4 \mathrm{~h} 30 \mathrm{~min}$ postfertilization; every $15 \mathrm{~min}$ until $7 \mathrm{~h}$ post-fertilization; every $20 \mathrm{~min}$ until $11 \mathrm{~h}$ post-fertilization; and every 30 min until hatching.

Embryos aliquots from each batch were observed using a stereomicroscope (Nikon SMZ 1500, Nikon, Tokyo, Japan) with a charge coupled device (CCD) camera (Nikon DS-Fi, Nikon, Japan). Digital images were captured using NIS-AR Elements software (Nikon, Tokyo, Japan). The embryonic development of P. maculatus and P. mangurus was classified into zygote, cleavage, blastula, gastrula, segmentation, and hatching stages, and each period was subdivided into phases based on previous studies (Fujimoto et al., 2006), (Dos Santos et al., 2016) and (Kimmel et al., 1995)

\section{Statistics}

Data are shown as the mean \pm standard error. Data were obtained in triplicate for which different egg batches were considered as a replicate. Percentages of embryos in each of the developmental stages were analyzed with analysis of variance (ANOVA), followed by Tukey multiple range test. In all analyses, the software STATISTICA (7.0, StatSoft, USA) was used with the probability set at 0.05 .

\section{Results}

\section{Embryogenesis}

Developmental stages of $P$. maculatus and P. mangurus at different incubation temperatures are presented on Tables 1 and 2. In the following topics, a detailed description of the developmental stages for both species is shown according to each temperature.

\section{Cleavage period}

After fertilization and hydration, the chorion begins to expand, inducing growth of the perivitelline space. The cytoplasm begins to migrate, forming the animal pole, initiating the formation of the blastocyst that covers the yolk in the animal pole, in which a meroblastic cleavage pattern occurs.

2-cell stage. In P. maculatus, embryos reached the 2cell stage at $45 \mathrm{~min}$ post-fertilization when incubated at $22^{\circ} \mathrm{C}, 30 \mathrm{~min}$ post-fertilization when incubated at $26^{\circ} \mathrm{C}$, and $25 \mathrm{~min}$ post-fertilization when incubated at $30^{\circ} \mathrm{C}$ (Fig. $1 B$ ). For P. mangurus, cleavage occurred $1 \mathrm{~h}$ post-fertilization when incubated at $22^{\circ} \mathrm{C}, 40 \mathrm{~min}$ postfertilization when incubated at $26^{\circ} \mathrm{C}$, and 25 min postfertilization when incubated at $30^{\circ} \mathrm{C}$ (Fig. 2B).

4-cell stage. In this stage, the initial two cells (blastomeres) divide symmetrically giving rise to four cells $1 \mathrm{~h}$ post-fertilization when incubated at $22^{\circ} \mathrm{C}$, $40 \mathrm{~min}$ post-fertilization at $26^{\circ} \mathrm{C}$, and $35 \mathrm{~min}$ postfertilization at $30^{\circ} \mathrm{C}$ in $P$. maculatus (Fig $1 C$ ). This occurred $1 \mathrm{~h} 20 \mathrm{~min}$ post-fertilization for $P$. mangurus when incubated at $22^{\circ} \mathrm{C}$, $55 \mathrm{~min}$ post-fertilization at $26^{\circ} \mathrm{C}$, and $35 \mathrm{~min}$ post-fertilization at $30^{\circ} \mathrm{C}$ (Fig. $2 \mathrm{C}$ ).

8 -cell stage. During the third stage of cleavage, the four cells of last stage divide symmetrically in a set of eight blastomeres, arranged in two 4-cell lines on the yolk. In $P$. maculatus, this stage occurs $1 \mathrm{~h} 10$ min post-fertilization when incubated at $22^{\circ} \mathrm{C}, 55 \mathrm{~min}$ post-fertilization at $26^{\circ} \mathrm{C}$, and $40 \mathrm{~min}$ post-fertilization at $30^{\circ} \mathrm{C}$ (Fig. 1D). For P. mangurus, eight cells were observed $1 \mathrm{~h} 35 \mathrm{~min}$ post-fertilization when incubated at $22^{\circ} \mathrm{C}, 1 \mathrm{~h} 5 \mathrm{~min}$ post-fertilization at $26^{\circ} \mathrm{C}$, and $45 \mathrm{~min}$ post-fertilization at $30^{\circ} \mathrm{C}($ Fig $2 D)$.

16-cell stage. The fourth stage of the cleavage has 16 cells symmetrically arranged in an arrangement of four rows of four cells each. In P. maculatus, this stage begins $1 \mathrm{~h} 35 \mathrm{~min}$ post-fertilization when incubated at $22^{\circ} \mathrm{C}, 1 \mathrm{~h} 5 \mathrm{~min}$ post-fertilization at $26^{\circ} \mathrm{C}$, and $50 \mathrm{~min}$ post-fertilization at $30^{\circ} \mathrm{C}$ (Fig. $1 E$ ). For P. mangurus, the fourth cleavage stage was observed $1 \mathrm{~h} 50 \mathrm{~min}$ postfertilization when incubated at $22^{\circ} \mathrm{C}, 1 \mathrm{~h} 15 \mathrm{~min}$ postfertilization at $26^{\circ} \mathrm{C}$, and $1 \mathrm{~h}$ post-fertilization at $30^{\circ}$ (Fig. 2E).

32-cell stage. The 16 cells divide again, and the blastocyst now consists of 32 blastomeres, arranged in an arrangement of four rows of eight cells each. The cluster of cells begins to overlap irregularly. For $P$. maculatus, this stage begins $1 \mathrm{~h} 55 \mathrm{~min}$ post-fertilization when incubated at $22^{\circ} \mathrm{C}, 1 \mathrm{~h} 15 \mathrm{~min}$ post-fertilization at $26^{\circ} \mathrm{C}$, and $55 \mathrm{~min}$ post-fertilization at $30^{\circ} \mathrm{C}$ (Fig. $1 \mathrm{~F}$ ). For $P$. mangurus, this stage occurred after $2 \mathrm{~h} 15 \mathrm{~min}$ postfertilization when incubated at $22^{\circ} \mathrm{C}, 1 \mathrm{~h} 25 \mathrm{~min}$ postfertilization at $26^{\circ} \mathrm{C}$, and $1 \mathrm{~h} 15 \mathrm{~min}$ post-fertilization at $30^{\circ} \mathrm{C}$ (Fig. 2F).

64-cell stage. In the last stage of cleavage, the 32 cells divide giving rise to a 64-cell blastocyst. For 
Table 1 Range of embryonic development for Pimelodus maculatus incubated at temperatures of $22^{\circ} \mathrm{C}, 26^{\circ} \mathrm{C}$ and $30^{\circ} \mathrm{C}$

\begin{tabular}{|c|c|c|c|c|c|}
\hline \multirow[b]{2}{*}{ Period } & \multirow[b]{2}{*}{ Stage } & \multicolumn{3}{|c|}{ Time to stage } & \multirow[b]{2}{*}{ Fig. no. } \\
\hline & & 22 & 26 & 30 & \\
\hline \multirow[t]{6}{*}{ Cleavage } & 2-cell & $45 \mathrm{~min}$ & $30 \mathrm{~min}$ & $25 \mathrm{~min}$ & $1 B$ \\
\hline & 4-cell & $1 \mathrm{~h}$ & $40 \mathrm{~min}$ & $35 \mathrm{~min}$ & $1 C$ \\
\hline & 8-cell & $1 \mathrm{~h} 10 \mathrm{~min}$ & $55 \mathrm{~min}$ & $40 \mathrm{~min}$ & $1 D$ \\
\hline & 16-cell & $1 \mathrm{~h} 35 \mathrm{~min}$ & $1 \mathrm{~h} 5 \mathrm{~min}$ & $50 \mathrm{~min}$ & $1 E$ \\
\hline & 32-cell & $1 \mathrm{~h} 55 \mathrm{~min}$ & $1 \mathrm{~h} 15 \mathrm{~min}$ & $55 \mathrm{~min}$ & $1 F$ \\
\hline & 64-cell & $2 \mathrm{~h} 15 \mathrm{~min}$ & $1 \mathrm{~h} 25 \mathrm{~min}$ & $1 \mathrm{~h} 5 \mathrm{~min}$ & $1 G$ \\
\hline \multirow[t]{7}{*}{ Blastula } & 128-cell & $2 \mathrm{~h} 45 \mathrm{~min}$ & $1 \mathrm{~h} 40 \mathrm{~min}$ & $1 \mathrm{~h} 15 \mathrm{~min}$ & $1 H$ \\
\hline & 256-cell & $3 \mathrm{~h} 10 \mathrm{~min}$ & $1 \mathrm{~h} 50 \mathrm{~min}$ & $1 \mathrm{~h} 25 \mathrm{~min}$ & $1 I$ \\
\hline & 512-cell & $3 \mathrm{~h} 30 \mathrm{~min}$ & $2 \mathrm{~h}$ & $1 \mathrm{~h} 35 \mathrm{~min}$ & $1 J$ \\
\hline & 1000-cell & $3 \mathrm{~h} 50 \mathrm{~min}$ & $2 \mathrm{~h} 15 \mathrm{~min}$ & $1 \mathrm{~h} 45 \mathrm{~min}$ & $1 K$ \\
\hline & Elongation & $4 \mathrm{~h} 5 \mathrm{~min}$ & $2 \mathrm{~h} 30 \mathrm{~min}$ & $1 \mathrm{~h} 55 \mathrm{~min}$ & $1 L$ \\
\hline & Spherical & $4 \mathrm{~h} 45 \mathrm{~min}$ & $3 \mathrm{~h}$ & $2 \mathrm{~h} 5 \mathrm{~min}$ & $1 M$ \\
\hline & Dome & $5 \mathrm{~h} 15 \mathrm{~min}$ & $3 \mathrm{~h} 20 \mathrm{~min}$ & $2 \mathrm{~h} 20 \mathrm{~min}$ & $1 N$ \\
\hline \multirow[t]{6}{*}{ Gastrula } & $25 \%$ epiboly & $5 \mathrm{~h} 45 \mathrm{~min}$ & $3 \mathrm{~h} 40 \mathrm{~min}$ & $2 \mathrm{~h} 45 \mathrm{~min}$ & 10 \\
\hline & $50 \%$ epiboly & $6 \mathrm{~h} 20 \mathrm{~min}$ & $4 \mathrm{~h} 5 \mathrm{~min}$ & $3 \mathrm{~h} 5 \mathrm{~min}$ & $1 P$ \\
\hline & Germ ring & $6 \mathrm{~h} 20 \mathrm{~min}$ & $4 \mathrm{~h} 10 \mathrm{~min}$ & $3 \mathrm{~h} 15 \mathrm{~min}$ & $1 Q$ \\
\hline & $75 \%$ epiboly & $7 \mathrm{~h}$ & $4 \mathrm{~h} 40 \mathrm{~min}$ & $3 \mathrm{~h} 45 \mathrm{~min}$ & $1 \widetilde{R}$ \\
\hline & $90 \%$ epiboly & $8 \mathrm{~h} 20 \mathrm{~min}$ & $5 \mathrm{~h} 30 \mathrm{~min}$ & $3 \mathrm{~h} 55 \mathrm{~min}$ & $1 S$ \\
\hline & $100 \%$ epiboly & $10 \mathrm{~h} 30 \mathrm{~min}$ & $6 \mathrm{~h} 30 \mathrm{~min}$ & $5 \mathrm{~h}$ & $2 T$ \\
\hline \multirow[t]{5}{*}{ Segmentation } & 3 somites & $12 \mathrm{~h} 15 \mathrm{~min}$ & $8 \mathrm{~h}$ & $6 \mathrm{~h}$ & $3 B$ \\
\hline & Optic vesicle & $12 \mathrm{~h} 30 \mathrm{~min}$ & $8 \mathrm{~h} 20 \mathrm{~min}$ & $6 \mathrm{~h} 15 \mathrm{~min}$ & $3 D$ \\
\hline & Otic vesicle & $14 \mathrm{~h} 30 \mathrm{~min}$ & $9 \mathrm{~h} 20 \mathrm{~min}$ & $7 \mathrm{~h}$ & $3 K$ \\
\hline & Kupffer's vesicle & $14 \mathrm{~h}$ & $10 \mathrm{~h} 20 \mathrm{~min}$ & $7 \mathrm{~h} 30 \mathrm{~min}$ & $3 F$ \\
\hline & Kupffer's vesicle disappearance & $16 \mathrm{~h} 30 \mathrm{~min}$ & $11 \mathrm{~h} 30 \mathrm{~min}$ & $8 \mathrm{~h}$ & \\
\hline Hatching & & $22 \mathrm{~h} 30 \mathrm{~min}$ & $16 \mathrm{~h} 30 \mathrm{~min}$ & $11 \mathrm{~h} 20 \mathrm{~min}$ & $5 A$ \\
\hline
\end{tabular}

P. maculatus, it occurred $2 \mathrm{~h} 15 \mathrm{~min}$ post-fertilization when incubated at $22^{\circ} \mathrm{C}, 1 \mathrm{~h} 25 \mathrm{~min}$ post-fertilization at $26^{\circ} \mathrm{C}$, and $1 \mathrm{~h} 5 \mathrm{~min}$ post-fertilization at $30^{\circ} \mathrm{C}$ (Fig. $1 \mathrm{G}$ ). $P$. mangurus reached this stage $2 \mathrm{~h} 30 \mathrm{~min}$ postfertilization when incubated at $22^{\circ} \mathrm{C}, 1 \mathrm{~h} 40 \mathrm{~min}$ postfertilization at $26^{\circ} \mathrm{C}$, and $1 \mathrm{~h} 30 \mathrm{~min}$ post-fertilization at $30^{\circ} \mathrm{C}$ (Fig. $2 \mathrm{G}$ ).

\section{Blastula period}

The blastula period is divided into the following stages: 128 cells, 256 cells, 512 cells, over 1000 cells, elongation, spherical, and dome. The cells were now arranged irregularly and overlapping each other on the yolk.

128-cell stage. For P. maculatus embryos, this stage began $2 \mathrm{~h} 45 \mathrm{~min}$ post-fertilization, when incubated at $22^{\circ} \mathrm{C}, 1 \mathrm{~h} 40 \mathrm{~min}$ post-fertilization at $26^{\circ} \mathrm{C}$, and 1 h $15 \mathrm{~min}$ post-fertilization at $30^{\circ} \mathrm{C}$ (Fig. $1 \mathrm{H}$ ). For $P$. mangurus, the cells reached this stage $3 \mathrm{~h} 20 \mathrm{~min}$ postfertilization when incubated at $22^{\circ} \mathrm{C}, 1 \mathrm{~h} 55 \mathrm{~min}$ postfertilization at $26^{\circ} \mathrm{C}$, and $1 \mathrm{~h} 45 \mathrm{~min}$ post-fertilization at $30^{\circ} \mathrm{C}$ (Fig. $2 \mathrm{H}$ ).

256-cell stage. Pimelodus maculatus embryos achieve the second stage of the blastula after $3 \mathrm{~h} 10 \mathrm{~min}$ postfertilization when incubated at $22^{\circ} \mathrm{C}, 1 \mathrm{~h} 50 \mathrm{~min}$ postfertilization at $26^{\circ} \mathrm{C}$, and $1 \mathrm{~h} 25 \mathrm{~min}$ post-fertilization at $30^{\circ} \mathrm{C}$ (Fig. 1I). For P. mangurus, the cells reached this stage $4 \mathrm{~h}$ post-fertilization when incubated at $22^{\circ} \mathrm{C}$, $2 \mathrm{~h} 15 \mathrm{~min}$ post-fertilization at $26^{\circ} \mathrm{C}$, and $2 \mathrm{~h}$ postfertilization at $30^{\circ} \mathrm{C}$ (Fig. 2I).

512-cell stage. The embryos of $P$. maculatus started this stage $3 \mathrm{~h} 30 \mathrm{~min}$ post-fertilization at $22^{\circ} \mathrm{C}, 2 \mathrm{~h}$ postfertilization at $26^{\circ} \mathrm{C}$, and $1 \mathrm{~h} 35 \mathrm{~min}$ post-fertilization at $30^{\circ} \mathrm{C}$ (Fig. 1J). For P. mangurus, this stage was reached $4 \mathrm{~h} 30 \mathrm{~min}$ post-fertilization at $22^{\circ} \mathrm{C}, 2 \mathrm{~h} 30 \mathrm{~min}$ postfertilization at $26^{\circ} \mathrm{C}$, and $2 \mathrm{~h} 15 \mathrm{~min}$ post-fertilization at $30^{\circ} \mathrm{C}$ (Fig 2J).

1000-cell stage. Pimelodus maculatus embryos reached this stage $3 \mathrm{~h} 50 \mathrm{~min}$ post-fertilization when incubated at $22^{\circ} \mathrm{C}, 2 \mathrm{~h} 15 \mathrm{~min}$ post-fertilization at $26^{\circ} \mathrm{C}$, and $1 \mathrm{~h} 45$ min post-fertilization at $30^{\circ} \mathrm{C}$ (Fig $\left.1 \mathrm{~K}\right)$. Pseudopimelodus mangurus reached this stage $5 \mathrm{~h}$ post-fertilization when incubated at $22^{\circ} \mathrm{C}, 2 \mathrm{~h} 50 \mathrm{~min}$ post-fertilization at $26^{\circ} \mathrm{C}$, and $2 \mathrm{~h} 40 \mathrm{~min}$ post-fertilization at $30^{\circ} \mathrm{C}$ (Fig 2K).

Elongation stage. Pimelodus maculatus embryos incubated at $22^{\circ} \mathrm{C}$ were observed $4 \mathrm{~h} 5 \mathrm{~min}$ postfertilization, $2 \mathrm{~h} 30 \mathrm{~min}$ post-fertilization at $26^{\circ} \mathrm{C}$, and $1 \mathrm{~h} 55 \mathrm{~min}$ post-fertilization at $30^{\circ} \mathrm{C}$ (Fig $1 L$ ). For $P$. mangurus, it took $5 \mathrm{~h} 45 \mathrm{~min}$ post-fertilization to reach this stage when incubated at $22^{\circ} \mathrm{C}, 3 \mathrm{~h} 10 \mathrm{~min}$ 
Table 2 Range of embryonic development for Pseudopimelodus mangurus incubated at temperatures of $22^{\circ} \mathrm{C}, 26^{\circ} \mathrm{C}$ and $30^{\circ} \mathrm{C}$

\begin{tabular}{|c|c|c|c|c|c|}
\hline \multirow[b]{2}{*}{ Period } & \multirow[b]{2}{*}{ Stage } & \multicolumn{3}{|c|}{ Time to stage } & \multirow[b]{2}{*}{ Fig. no. } \\
\hline & & 22 & 26 & 30 & \\
\hline \multirow[t]{6}{*}{ Cleavage } & 2-cell & $1 \mathrm{~h}$ & $40 \mathrm{~min}$ & $25 \mathrm{~min}$ & $2 B$ \\
\hline & 4-cell & $1 \mathrm{~h} 20 \mathrm{~min}$ & $55 \mathrm{~min}$ & $35 \mathrm{~min}$ & $2 C$ \\
\hline & 8-cell & $1 \mathrm{~h} 35 \mathrm{~min}$ & $1 \mathrm{~h} 5 \mathrm{~min}$ & $45 \mathrm{~min}$ & $2 D$ \\
\hline & 16-cell & $1 \mathrm{~h} 50 \mathrm{~min}$ & $1 \mathrm{~h} 15 \min$ & $1 \mathrm{~h}$ & $2 E$ \\
\hline & 32-cell & 2 h $15 \min$ & $1 \mathrm{~h} 25 \min$ & $1 \mathrm{~h} 15 \mathrm{~min}$ & $2 F$ \\
\hline & 64-cell & 2 h $30 \mathrm{~min}$ & $1 \mathrm{~h} 40 \mathrm{~min}$ & $1 \mathrm{~h} 30 \mathrm{~min}$ & $2 G$ \\
\hline \multirow[t]{7}{*}{ Blastula } & 128-cell & $3 \mathrm{~h} 20 \mathrm{~min}$ & $1 \mathrm{~h} 55 \min$ & $1 \mathrm{~h} 45 \mathrm{~min}$ & $2 \mathrm{H}$ \\
\hline & 256-cell & $4 \mathrm{~h}$ & 2 h $15 \min$ & $2 \mathrm{~h}$ & $2 I$ \\
\hline & 512-cell & $4 \mathrm{~h} 30 \mathrm{~min}$ & $2 \mathrm{~h} 30 \mathrm{~min}$ & $2 \mathrm{~h} 15 \mathrm{~min}$ & $2 J$ \\
\hline & 1000-cell & $5 \mathrm{~h}$ & 2 h 50 min & $2 \mathrm{~h} 40 \mathrm{~min}$ & $2 K$ \\
\hline & Elongation & 5 h 45 min & $3 \mathrm{~h} 10 \mathrm{~min}$ & $3 \mathrm{~h}$ & $2 L$ \\
\hline & Spherical & $6 \mathrm{~h} 30 \mathrm{~min}$ & 3 h $50 \mathrm{~min}$ & $3 \mathrm{~h} 20 \mathrm{~min}$ & $2 M$ \\
\hline & Dome & $7 \mathrm{~h} 25 \mathrm{~min}$ & $4 \mathrm{~h} 20 \mathrm{~min}$ & $3 \mathrm{~h} 40 \mathrm{~min}$ & $2 N$ \\
\hline \multirow{11}{*}{ Gastrula } & $25 \%$ epiboly & $7 \mathrm{~h} 40 \mathrm{~min}$ & $4 \mathrm{~h} 30 \mathrm{~min}$ & $4 \mathrm{~h}$ & $2 O$ \\
\hline & $50 \%$ epiboly & $8 \mathrm{~h} 40 \mathrm{~min}$ & 5 h 15 min & $4 \mathrm{~h} 15 \mathrm{~min}$ & $2 P$ \\
\hline & Germ ring & $8 \mathrm{~h} 40 \mathrm{~min}$ & 5 h 15 min & $4 \mathrm{~h} 15 \mathrm{~min}$ & $2 Q$ \\
\hline & $75 \%$ epiboly & $9 \mathrm{~h} 40 \mathrm{~min}$ & 5 h 45 min & $4 \mathrm{~h} 45 \mathrm{~min}$ & $2 R$ \\
\hline & $90 \%$ epiboly & $10 \mathrm{~h} 40 \mathrm{~min}$ & $6 \mathrm{~h} 30 \mathrm{~min}$ & $5 \mathrm{~h} 30 \mathrm{~min}$ & $2 S$ \\
\hline & $100 \%$ epiboly & $12 \mathrm{~h} 30 \mathrm{~min}$ & $7 \mathrm{~h} 20 \mathrm{~min}$ & $6 \mathrm{~h}$ & $2 T$ \\
\hline & 3 somites & $14 \mathrm{~h}$ & $9 \mathrm{~h}$ & - & $4 B$ \\
\hline & Optic vesicle & $15 \mathrm{~h}$ & $9 \mathrm{~h} 20 \mathrm{~min}$ & - & $4 G$ \\
\hline & Otic vesicle & $16 \mathrm{~h}$ & $11 \mathrm{~h}$ & - & $4 L$ \\
\hline & Kupffer's vesicle & $18 \mathrm{~h} 30 \mathrm{~min}$ & $11 \mathrm{~h}$ & - & $4 J$ \\
\hline & Kupffer's vesicle disappearance & $21 \mathrm{~h}$ & $13 \mathrm{~h} 30 \mathrm{~min}$ & - & \\
\hline Hatching & & $28 \mathrm{~h} 30 \mathrm{~min}$ & $17 \mathrm{~h} 30 \mathrm{~min}$ & - & $5 B$ \\
\hline
\end{tabular}

post-fertilization at $26^{\circ} \mathrm{C}$, and $3 \mathrm{~h}$ post-fertilization at $30^{\circ} \mathrm{C}$ (Fig. $2 L$ ).

Spherical stage. The cell pellet was already organized on the yolk forming a ball shape. P. maculatus embryos reached this stage $4 \mathrm{~h} 45 \mathrm{~min}$ post-fertilization when incubated at $22^{\circ} \mathrm{C}, 3 \mathrm{~h}$ post-fertilization at $26^{\circ} \mathrm{C}$, and $2 \mathrm{~h} 5 \mathrm{~min}$ post-fertilization at $30^{\circ} \mathrm{C}$ (Fig. $1 \mathrm{M}$ ). Pseudopimelodus mangurus embryos took $6 \mathrm{~h} 30 \mathrm{~min}$ post-fertilization to reach this stage when incubated at $22^{\circ} \mathrm{C}, 3 \mathrm{~h} 50 \mathrm{~min}$ post-fertilization at $26^{\circ} \mathrm{C}$, and $3 \mathrm{~h} 20$ min post-fertilization at $30^{\circ} \mathrm{C}$ (Fig. $2 \mathrm{M}$ ).

Dome stage. The group of cells began to cover the whole yolk in epiboly movement. For P. maculatus, this stage occurred $5 \mathrm{~h} 15$ min post-fertilization when the embryos were incubated at $22^{\circ} \mathrm{C}, 3 \mathrm{~h} 20 \mathrm{~min}$ postfertilization at $26^{\circ} \mathrm{C}$, and $2 \mathrm{~h} 20 \mathrm{~min}$ post-fertilization at $30^{\circ} \mathrm{C}$ (Fig. $1 \mathrm{~N}$ ). For P. mangurus, embryos took $7 \mathrm{~h}$ 25 min post-fertilization to reach dome stage when incubated at $22^{\circ} \mathrm{C}, 4 \mathrm{~h} 20 \mathrm{~min}$ post-fertilization at $26^{\circ} \mathrm{C}$, and $3 \mathrm{~h} 40 \mathrm{~min}$ post-fertilization at $30^{\circ} \mathrm{C}$ (Fig. $2 \mathrm{~N}$ ).

\section{Gastrula period}

During this period, epiboly were observed. The blastoderm converged and extended on the yolk. The stages in this period were divided according to the percentage of the yolk that was covered by the blastoderm.

$25 \%$ epiboly stage. A quarter of the yolk was covered by the blastoderm. Pimelodus maculatus arrived at this stage $5 \mathrm{~h} 45 \mathrm{~min}$ post-fertilization at $22^{\circ} \mathrm{C}, 3 \mathrm{~h} 40$ min post-fertilization at $26^{\circ} \mathrm{C}$, and $2 \mathrm{~h} 45 \mathrm{~min}$ postfertilization when incubated at $30^{\circ} \mathrm{C}$ (Fig. 1O). For $P$. mangurus, embryos were observed covering a quarter of the yolk $7 \mathrm{~h} 40 \mathrm{~min}$ post-fertilization when incubated at $22^{\circ} \mathrm{C}, 4 \mathrm{~h} 30 \mathrm{~min}$ post-fertilization at $26^{\circ} \mathrm{C}$, or $4 \mathrm{~h}$ postfertilization at $30^{\circ} \mathrm{C}$ (Fig. 2O).

$50 \%$ epiboly stage. Half of the yolk was covered by the blastoderm in this stage. For P. maculatus, half of the yolk was covered $6 \mathrm{~h} 20 \mathrm{~min}$ post-fertilization at $22^{\circ} \mathrm{C}, 4 \mathrm{~h} 5 \mathrm{~min}$ post-fertilization $26^{\circ} \mathrm{C}$, and $3 \mathrm{~h} 5$ min post-fertilization when incubated at $30^{\circ} \mathrm{C}$ (Fig. $1 P$ ). Pseudopimelodus mangurus embryos were observed at this stage $8 \mathrm{~h} 40 \mathrm{~min}$ post-fertilization at $22^{\circ} \mathrm{C}, 5 \mathrm{~h} 15$ min post-fertilization at $26^{\circ} \mathrm{C}$, and $4 \mathrm{~h} 15 \mathrm{~min}$ postfertilization at $30^{\circ} \mathrm{C}$ (Fig. $2 P$ ). During this stage, it was also observed that there was a germinative ring for $P$. maculatus and P. mangurus (Fig. 1Q, 2Q).

$75 \%$ epiboly stage. Three-quarters of the yolk was covered by the blastoderm. Pimelodus maculatus embryos arrived at this stage at $7 \mathrm{~h}$ post-fertilization 


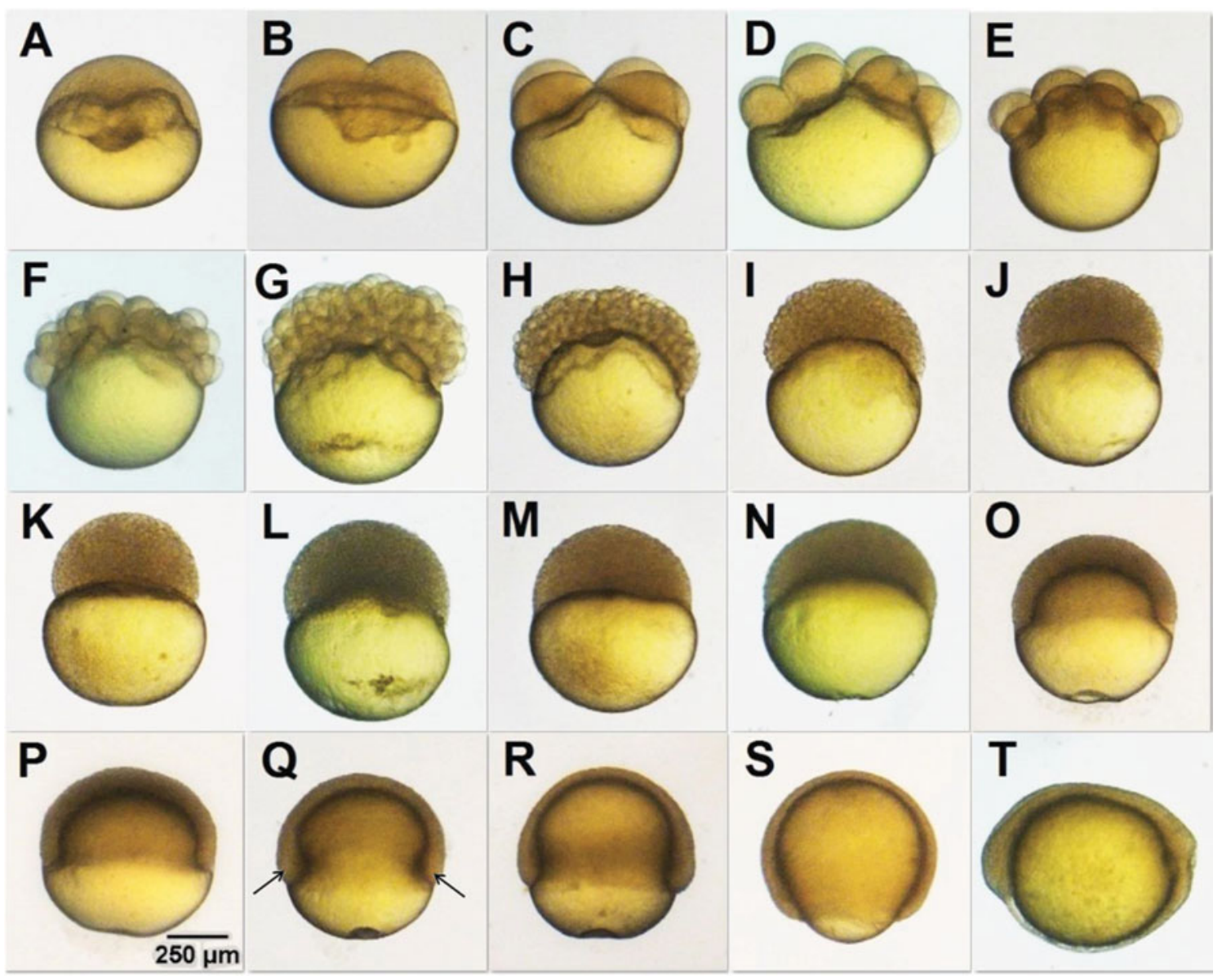

Figure 1 Embryonic development of $P$. maculatus, at period of cleavage, blastula, gastrula and initial segmentation. $(A)$ Animal pole differentiation; $(B)$ 2-cell stage; $(C)$ 4-cell stage; $(D)$ 8-cell stage; $(E)$ 16-cell stage; $(F)$ 32-cell stage; $(G)$ 64-cell stage; $(H)$ initial blastula stage with 128 blastomeres; $(I) 256$ blastomeres stage; $(J)$ stage of 512 blastomeres; $(K)$ stage with more than1000 blastomeres; $(L)$ elongation stage; $(M)$ spherical stage; $(N)$ dome stage; $(O)$ initial gastrula stage with $25 \%$ of epiboly; $(P)$ $50 \%$ epiboly; $(Q)$ germ ring stage (arrows indicate the germ ring); $(R)$ 75\% epiboly stage; $(S)$ 90\% epiboly stage; $(T)$ initial segmentation stage (neurula stage). Scale bar indicates $250 \mu \mathrm{m}$.

when incubated at $22^{\circ} \mathrm{C}, 4 \mathrm{~h} 40 \mathrm{~min}$ post-fertilization at $26^{\circ} \mathrm{C}$, and $3 \mathrm{~h} 45 \mathrm{~min}$ post-fertilization when incubated at $30^{\circ} \mathrm{C}$ (Fig. 1R). Pseudopimelodus mangurus embryos reached this stage $9 \mathrm{~h} 40 \mathrm{~min}$ post-fertilization at $22^{\circ} \mathrm{C}$, $5 \mathrm{~h} 45 \mathrm{~min}$ post-fertilization at $26^{\circ} \mathrm{C}$, and $4 \mathrm{~h} 45 \mathrm{~min}$ post-fertilization at $30^{\circ} \mathrm{C}$ (Fig. $2 R$ ).

$90 \%$ epiboly stage. At this stage, $90 \%$ of the yolk was covered by the blastoderm. The embryos of $P$. maculatus arrive at this stage at $8 \mathrm{~h} 20 \mathrm{~min}$ postfertilization when incubated at $22^{\circ} \mathrm{C}, 5 \mathrm{~h} 30 \mathrm{~min}$ postfertilization at $26^{\circ} \mathrm{C}$, and $3 \mathrm{~h} 55 \mathrm{~min}$ post-fertilization at $30^{\circ} \mathrm{C}$ (Fig. $1 S$ ). P. mangurus embryos arrived at this stage $10 \mathrm{~h} 40 \mathrm{~min}$ post-fertilization at $22^{\circ} \mathrm{C}, 6 \mathrm{~h} 30$ min post-fertilization at $26^{\circ} \mathrm{C}$, and $5 \mathrm{~h} 30 \mathrm{~min}$ postfertilization at $30^{\circ} \mathrm{C}$ (Fig. $2 \mathrm{~S}$ ).

$100 \%$ epiboly stage. At this stage, $100 \%$ of the yolk was already covered by the blastoderm. $P$. maculatus embryos reached this stage $10 \mathrm{~h} 30 \mathrm{~min}$ post-fertilization when incubated at $22^{\circ} \mathrm{C}, 6 \mathrm{~h} 30 \mathrm{~min}$ post-fertilization at $26^{\circ} \mathrm{C}$, and $5 \mathrm{~h}$ post-fertilization when incubated at $30^{\circ} \mathrm{C}$ (Fig. 1T). For P. mangurus, the embryos took $12 \mathrm{~h} 30 \mathrm{~min}$ post-fertilization to arrive at this stage at $22^{\circ} \mathrm{C}, 7 \mathrm{~h} 20 \mathrm{~min}$ post-fertilization at $26^{\circ} \mathrm{C}$, and $6 \mathrm{~h}$ post-fertilization at $30^{\circ} \mathrm{C}$ (Fig. $2 \mathrm{~T}$ ).

\section{Segmentation period}

The segmentation period began in the neurula stage with the appearance of somites (Fig. $3 A, 4 A$ ) and differentiation of head and tail (Fig. 3B, 4B), and it ended with hatching (Fig. 5A, 5B). During this stage, the embryo began to develop its morphological structures, such as the optic vesicle, otic vesicle, Kupffer vesicle, and the onset of somatogenesis. Somites development occurs from the trunk to the tail of the embryo. This period is defined by the structures observed and by the number of somites. 

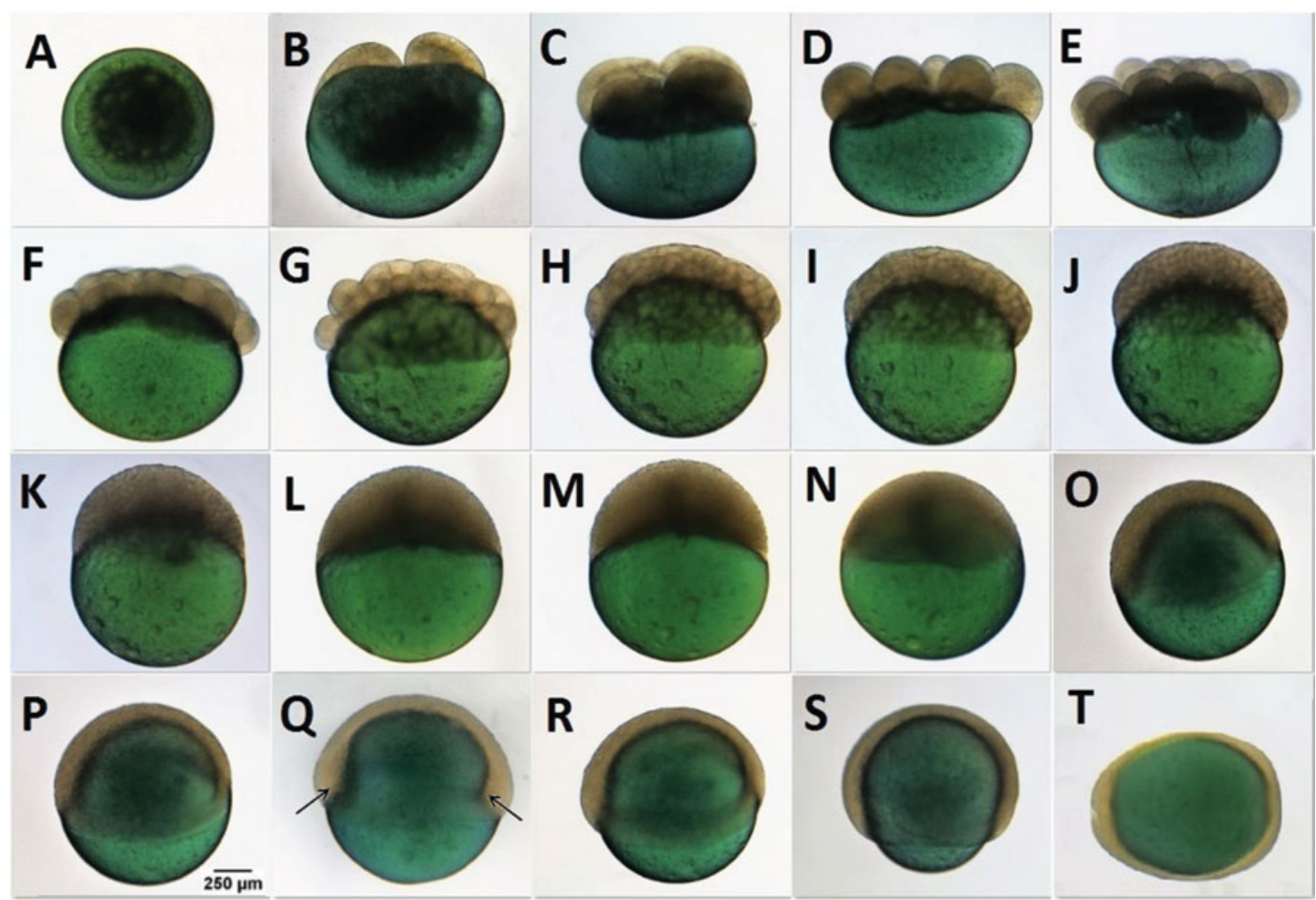

Figure 2 Embryonic development of $P$. mangurus, at period of cleavage, blastula, gastrula and initial segmentation. $(A)$ Animal pole differentiation; $(B)$ 2-cell stage; $(C)$ 4-cell stage; $(D)$ 8-cell stage; $(E)$ 16-cell stage; $(F)$ 32-cell stage; $(G)$ 64-cell stage; $(H)$ initial blastula stage with 128 blastomeres; $(I) 256$ blastomeres stage; $(J)$ stage of 512 blastomeres; $(K)$ stage with more than1000 blastomeres; $(L)$ elongation stage; $(M)$ spherical stage; $(N)$ dome stage; $(O)$ initial gastrula stage with $25 \%$ of epiboly; $(P)$ stage with 50\% epiboly; $(Q)$ germ ring stage (arrows indicate the germ ring); $(R) 75 \%$ epiboly stage; $(S)$ 90\% epiboly stage; $(T)$ initial segmentation stage (neurula stage). Scale bar indicates $250 \mu \mathrm{m}$.

During this period, a high mortality rate occurs during $P$. mangurus embryo incubation, resulting in $100 \%$ mortality when embryos are incubated at $30^{\circ} \mathrm{C}$.

In the $P$. maculatus embryos, the first somites appeared $12 \mathrm{~h} 15 \mathrm{~min}$ post-fertilization when incubated at $22^{\circ} \mathrm{C}, 8 \mathrm{~h}$ post-fertilization at $26^{\circ} \mathrm{C}$, and $6 \mathrm{~h}$ post-fertilization when incubated at $30^{\circ} \mathrm{C}$. For the $P$. mangurus, the first somites appeared $14 \mathrm{~h}$ postfertilization when incubated at $22^{\circ} \mathrm{C}$ and $9 \mathrm{~h}$ postfertilization at $26^{\circ} \mathrm{C}$.

The segmentation period ended at hatching. At this moment, the larvae broke out of the chorion and started free swimming

\section{Hatching period}

The embryonic development ended when the larvae broke out of the chorion. Larvae of P. mangurus incubated at $22^{\circ} \mathrm{C}$ hatched $28 \mathrm{~h} 30 \mathrm{~min}$ post-fertilization, presenting 37 somites; $17 \mathrm{~h} 30 \mathrm{~min}$ post-fertilization when incubated at $26^{\circ} \mathrm{C}$ with 35 somites; and no larvae hatched at $30^{\circ} \mathrm{C}$ (Fig. 5B). Pimelodus maculatus larvae hatched $22 \mathrm{~h} 30 \mathrm{~min}$ post-fertilization when incubated at $22^{\circ} \mathrm{C}$, presenting 32 somites, $16 \mathrm{~h} 30 \mathrm{~min}$ postfertilization when incubated at $26^{\circ} \mathrm{C}$ with 29 somites; and $11 \mathrm{~h} 20 \mathrm{~min}$ post-fertilization at $30^{\circ} \mathrm{C}$, having 27 somites (Fig. 5A).

\section{Oocyte size}

For P. mangurus, the size of oocytes non-hydrated, hydrated and perivitelline space was $1217.16 \pm 13.35$, $1790.95 \pm 18.38$ and $356.87 \pm 19.21 \mu \mathrm{m}$, respectively. While for P. maculatus it was $792.26 \pm 18.69,1134.76 \pm$ 19.46 , and $259.67 \pm 12.89 \mu \mathrm{m}$, respectively.

\section{Effect of temperature on embryonic development}

There was a large difference in embryo development time between the two species when incubated at $22^{\circ} \mathrm{C}$, $26^{\circ} \mathrm{C}$, or $30^{\circ} \mathrm{C}$. During $P$. maculatus incubation, the embryos incubated at $30^{\circ} \mathrm{C}$ hatched $11 \mathrm{~h} 10 \mathrm{~min}$ faster compared with the embryos incubated at $22^{\circ} \mathrm{C}$ and $5 \mathrm{~h} 10 \mathrm{~min}$ when compared with embryos incubated at $26^{\circ} \mathrm{C}$ (Table 1). In P. mangurus, the difference was $11 \mathrm{~h}$ between the temperatures of $22^{\circ} \mathrm{C}$ and $26^{\circ} \mathrm{C}$ 


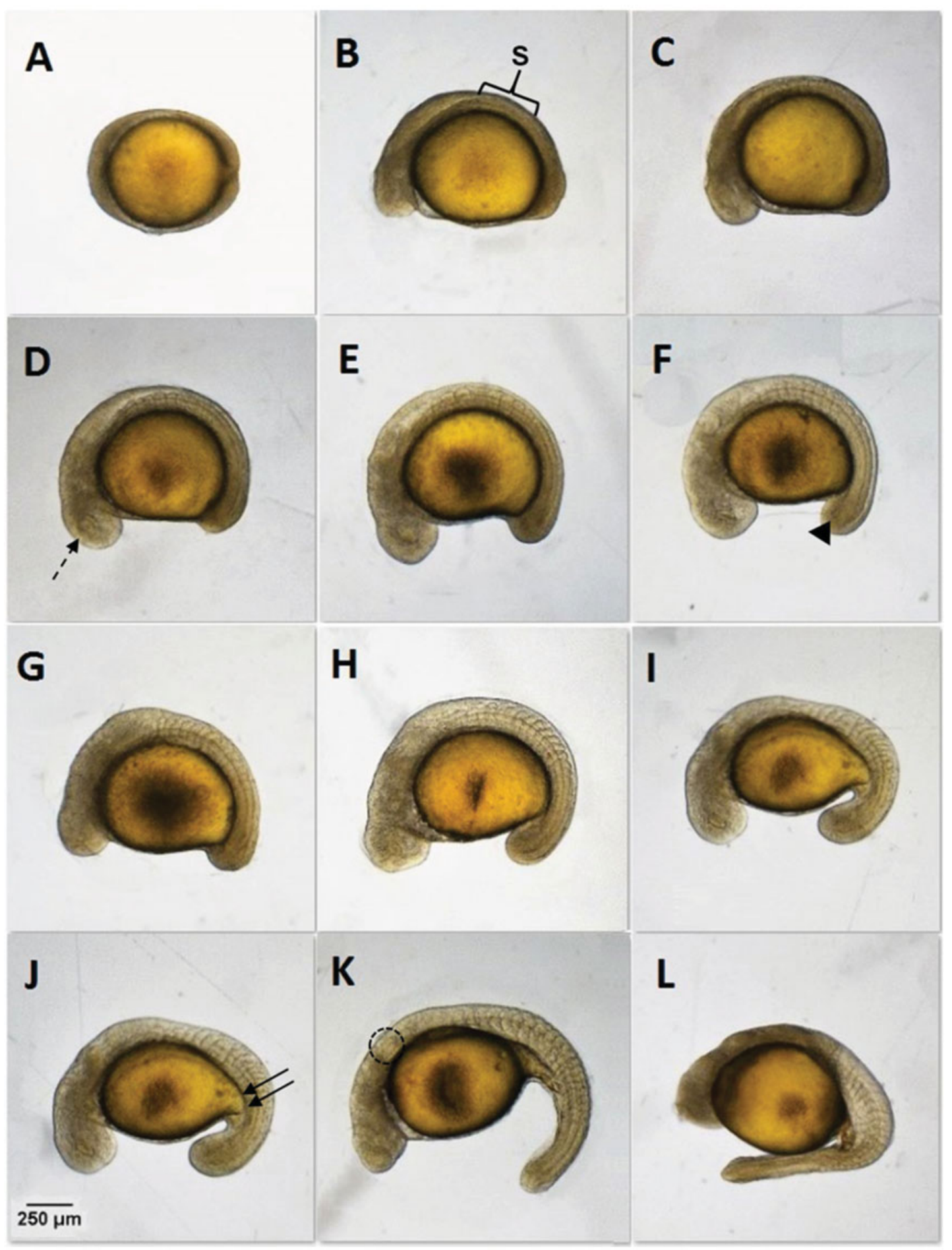

Figure 3 Embryos of $P$. maculatus during segmentation period, when incubated at $26^{\circ} \mathrm{C}$. $(A)$ Neurula stage; $(B) 3$-somite stage, brackets indicates the first somites $(S) ;(C)$ 5-somite stage; $(D)$ 8-somite stage, dashed arrow points the optic vesicle; $(E)$ 10somite stage; $(F)$ 12-somite stage (arrowhead indicates the Kupffer's vesicle); $(G)$ 14-somite stage; $(H)$ 15-somite stage; $(I)$ 20somite stage; $(J)$ 21-somite stage, double arrows indicate the elongation of the yolk; $(K) 24$-somite stage, dashed circle indicates otic vesicle; $(L)$ 28-somite stage. Scale bar indicates $250 \mu \mathrm{m}$. 


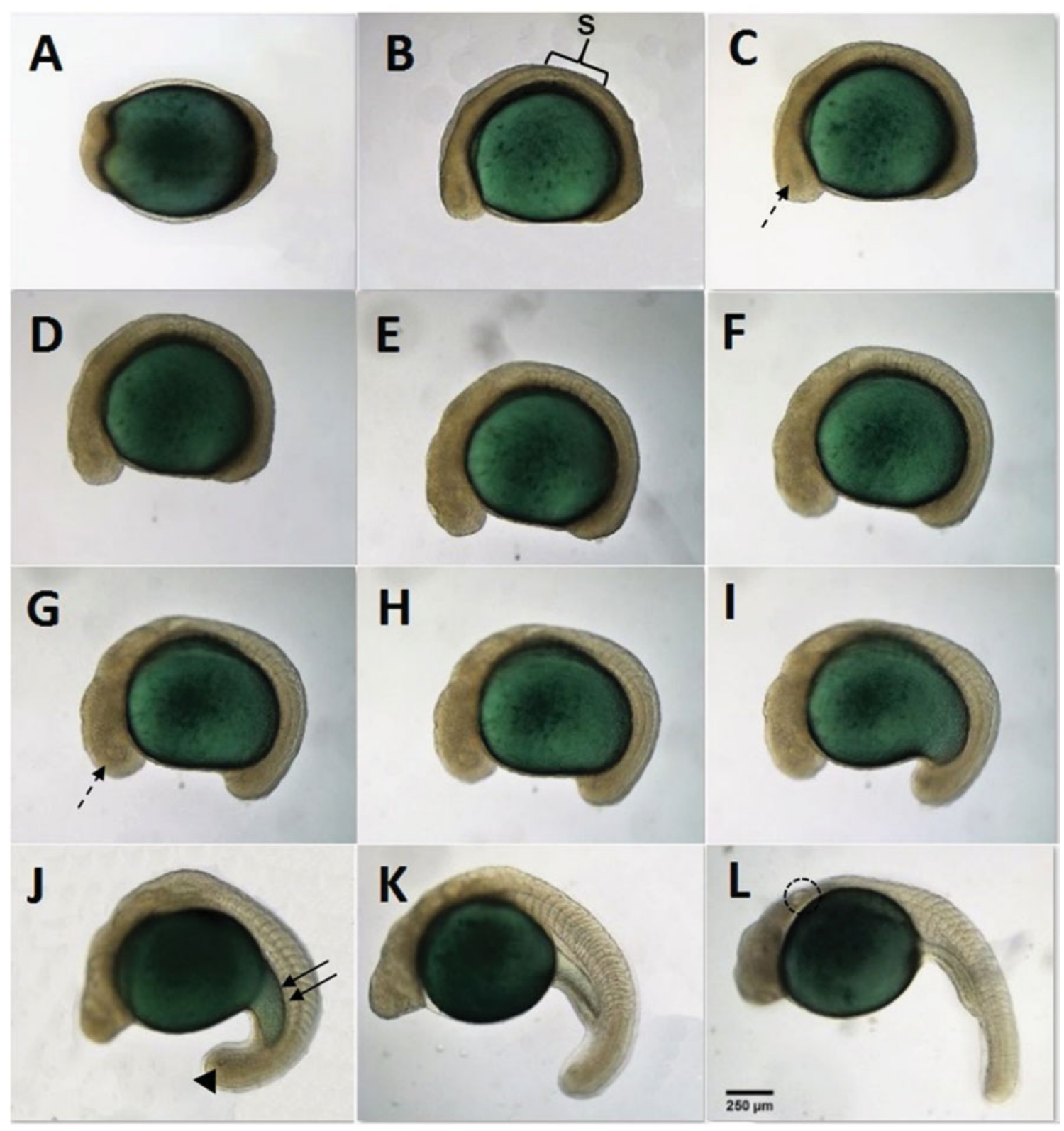

Figure 4 Embryos of $P$. mangurus during segmentation period when incubated at $26^{\circ} \mathrm{C}$. $(A)$ Neurula stage; $(B) 3$-somite stage, brackets indicates the first somites $(S) ;(C)$ 5-somite stage; $(D)$ 8-somite stage; $(E)$ 10-somite stage; $(F)$ 12-somite stage; $(G)$ 14somite stage, dashed arrow points the optic vesicle; $(H)$ 15-somite stage; $(I) 20$-somite stage; $(J)$ 21-somite stage, arrowhead indicates Kupffer's vesicle and double arrows indicate the elongation of the yolk; $(K)$ 24-somite stage; $(L)$ 28-somite stage, dashed circle indicates otic vesicle. Scale bar indicates $250 \mu \mathrm{m}$.

(Table 2). Warmer temperatures $\left(30^{\circ} \mathrm{C}\right)$ accelerated embryo development time in incubation, however, this led to a higher rate of abnormality among the $P$. maculatus larvae and caused the death of all $P$. mangurus embryos up to the segmentation period.

Temperature influenced embryonic development in $P$. maculatus and P. mangurus that were submitted to treatment, and higher and lower temperatures accelerate and decreased, respectively, embryonic development. Additionally, for both species, the larvae from the lower $\left(22^{\circ} \mathrm{C}\right)$ and higher temperatures $\left(30^{\circ} \mathrm{C}\right)$ also presented increased abnormality rates, as observed in the head (Fig. 6E, 6F), tail (Fig. 6C, 6D) and yolk regions (Fig. 6E, 6F). The lowest abnormality rate was observed at $26^{\circ} \mathrm{C}$, which was considered the optimal incubation temperature for both species. P. mangurus embryos showed tolerance to temperatures with a 45.4 $\pm 21.02 \%$ survival and $2.3 \pm 1.73 \%$ larvae abnormality when incubated at $22^{\circ} \mathrm{C}$, and presented $68.08 \pm$ $12.67 \%$ survival and $3.3 \pm 1.86 \%$ larvae abnormality 


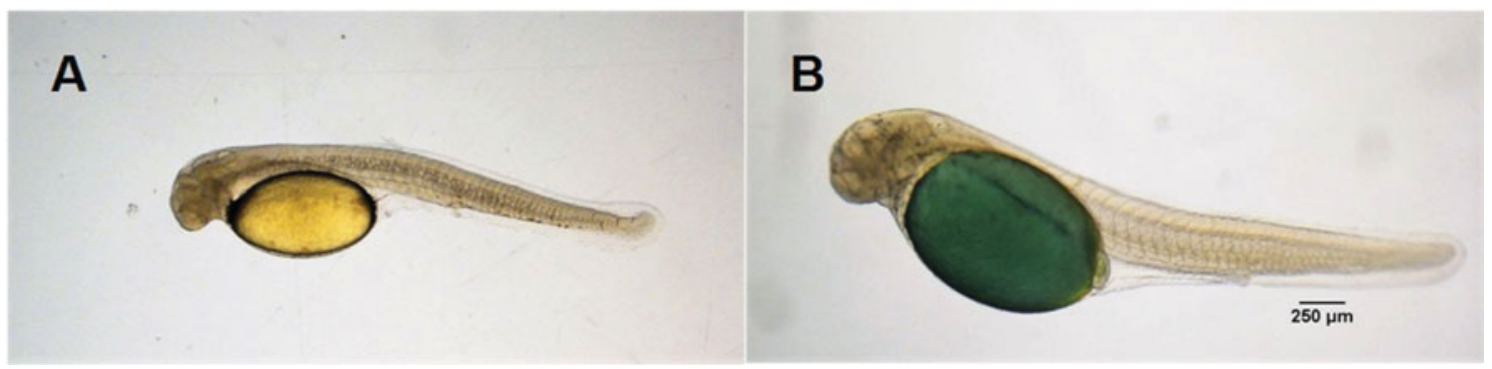

Figure 5 (A) Larvae of Pimelodus maculatus; (B) Pseudopimelodus mangurus after hatching. Scale bar indicates $250 \mu \mathrm{m}$.

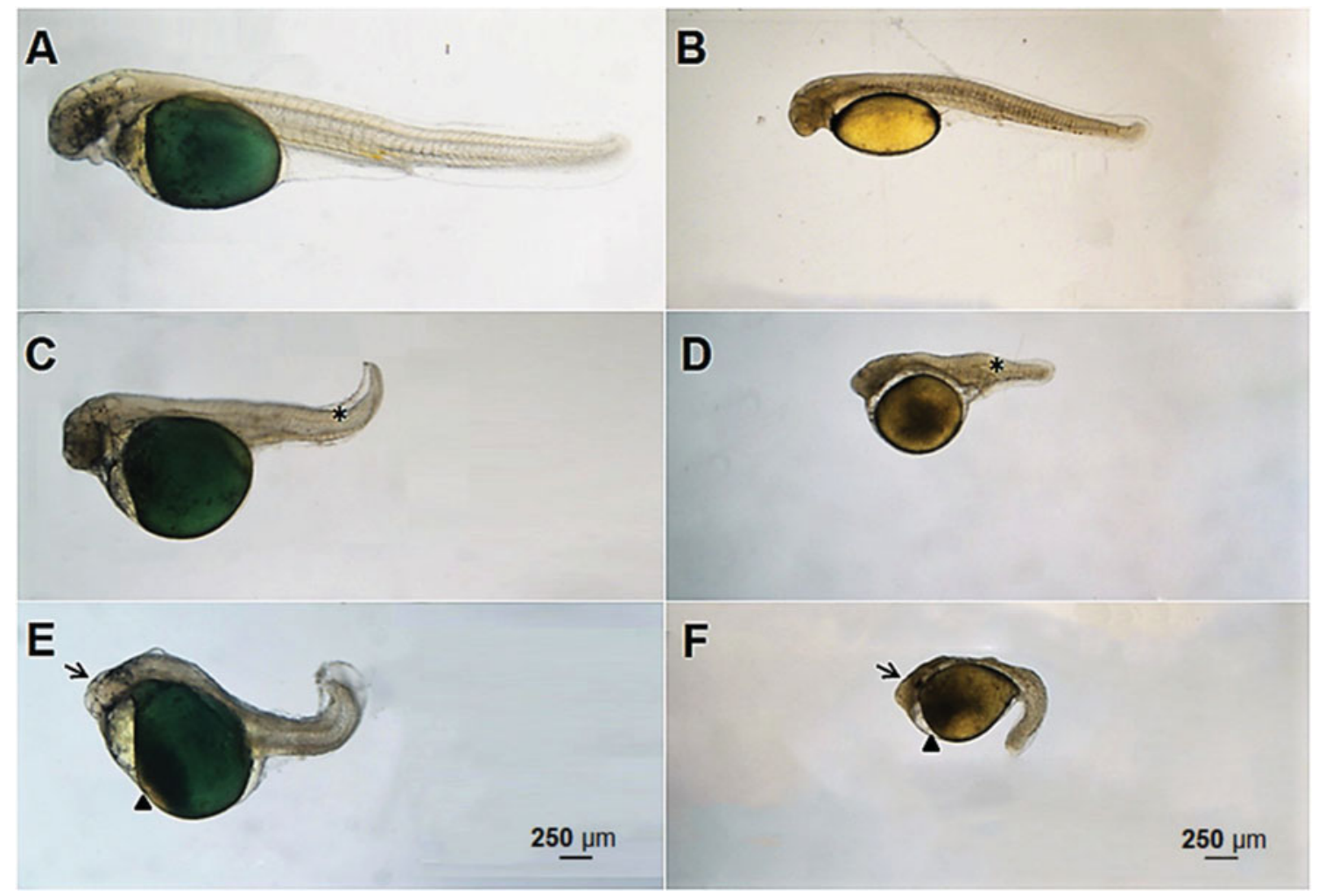

Figure 6 (A) Normal larvae of Pseudopimelodus mangurus. (B) Normal larvae of Pimelodus maculatus. (C) Larvae of Pseudopimelodus mangurus containing abnormality in caudal region (asterisk indicates abnormal tail). (D) Larvae of Pimelodus maculatus containing abnormality in caudal region (asterisk indicates abnormal tail). (E) Larvae of Pseudopimelodus mangurus containing abnormality in yolk and head region (arrow indicates the abnormal head and arrowhead indicates abnormal yolk region). (F) Larvae of Pimelodus maculatus containing abnormality in yolk and head region (arrow indicates the abnormal head and arrowhead indicates abnormal yolk region). Scale bar indicates $250 \mu \mathrm{m}$.

when incubated at $26^{\circ} \mathrm{C}$. When incubated at $30^{\circ} \mathrm{C}$, all embryos died before hatching (Table 3). Conversely, $P$. maculatus embryos hatched at all temperatures with a $20.13 \pm 19.8 \%$ survival rate and $21.84 \pm 2.37 \%$ larvae abnormality when incubated at $22^{\circ} \mathrm{C}$. When incubated at $26^{\circ} \mathrm{C}$, they presented a $57.57 \pm 17.49 \%$ survival rate and $10.79 \pm 4.17 \%$ larvae abnormality. At $30^{\circ} \mathrm{C}$, they presented a $53.63 \pm 16.27 \%$ survival rate and $20.76 \pm$ $7.45 \%$ larvae abnormality (Table 4 ).

\section{Discussion}

Defining the optimal temperature range for embryo incubation is a preliminary step for artificial propagation in fish species. Improvement in egg hatchability with less malformations is among the main parameters for evaluation of incubation temperatures (Pepin, 1991; Jordaan, 2002). As ectotherms, fish embryos may develop over a wide range of temperatures, in which 
Table 3 Percentage of main qualitative stages of embryonic development of Pseudopimelodus mangurus incubated at $22^{\circ} \mathrm{C}, 26^{\circ} \mathrm{C}$ or $30^{\circ} \mathrm{C}$

\begin{tabular}{lcccccccc}
\hline & \multicolumn{7}{c}{ Development stage (\%) } \\
\cline { 2 - 8 } Temperature & Unfertilized & 2-cell & Blastula & Gastrula & Segmentation & Hatching & Normal & Abnormal \\
\hline $22^{\circ} \mathrm{C}$ & $3.91 \pm 1.58$ & $96.09 \pm 1.58$ & $95.19 \pm 1.74$ & $88.69 \pm 5.18$ & $50.24 \pm 22.4^{a}$ & $45.36 \pm 21.02^{a}$ & $43.02 \pm 20.02$ & $2.34 \pm 1.73^{a}$ \\
$26^{\circ} \mathrm{C}$ & $2 \pm 0.63$ & $98 \pm 0.63$ & $95.85 \pm 1.57$ & $90.09 \pm 5.01$ & $72.66 \pm 12.7^{a}$ & $68.08 \pm 12.67^{a}$ & $64.76 \pm 11.95$ & $3.30 \pm 1.86^{a}$ \\
$30^{\circ} \mathrm{C}$ & $5.37 \pm 2.09$ & $94.63 \pm 2.09$ & $94.06 \pm 2.54$ & $84.42 \pm 7.22$ & $2.98 \pm 1.62^{b}$ & $0 \pm 0^{b}$ & $0 \pm 0$ & $0 \pm 0^{b}$ \\
$P$-value & 0.464 & 0.661 & 0.936 & 0.804 & 0.004 & 0.0003 & 0.246 & 0.0002 \\
\hline
\end{tabular}

${ }^{\mathrm{a}, \mathrm{b}}$ Values with different superscripts differ significantly.

Table 4 Percentage of main qualitative stages of embryonic development of Pimelodus maculatus incubated at $22^{\circ} \mathrm{C}, 26^{\circ} \mathrm{C}$ or $30^{\circ} \mathrm{C}$

\begin{tabular}{lcccccccc}
\hline & \multicolumn{7}{c}{ Development stage (\%) } \\
\cline { 2 - 9 } Temperature & Unfertilized & 2-cell & Blastula & Gastrula & Segmentation & Hatching & Normal & Abnormal \\
\hline $22^{\circ} \mathrm{C}$ & $3.05 \pm 1.79$ & $96.95 \pm 1.79$ & $88.45 \pm 9.43$ & $82.51 \pm 8.74$ & $66.67 \pm 7.11$ & $43.87 \pm 7.46$ & $20.13 \pm 19.8$ & $21.84 \pm 2.37$ \\
$26^{\circ} \mathrm{C}$ & $1.26 \pm 0.76$ & $98.74 \pm 0.76$ & $96.42 \pm 0.59$ & $92.88 \pm 1.17$ & $72.42 \pm 13.04$ & $57.57 \pm 17.49$ & $46.78 \pm 21.47$ & $10.79 \pm 4.17$ \\
$30^{\circ} \mathrm{C}$ & $1.55 \pm 0.19$ & $98.45 \pm 0.19$ & $90.35 \pm 8.04$ & $88.80 \pm 7.98$ & $64.35 \pm 17.89$ & $53.63 \pm 16.27$ & $32.87 \pm 21.9$ & $20.76 \pm 7.45$ \\
$P$-value & 0.786 & 0.786 & 0.899 & 0.612 & 0.929 & 0.777 & 0.257 & 0.649 \\
\hline
\end{tabular}


warmer temperatures increase the velocity of development and embryo formation (Dos Santos et al., 2016). However, such a range of incubation temperature is well known to be species specific, as observed in Atractosteus tristoechus $\left(26^{\circ} \mathrm{C}\right)$ (Comabella et al., 2014), Lota lota $\left(2^{\circ} \mathrm{C}\right)$ (Lahnsteiner et al., 2012), Rhamdia quelen $\left(21-30^{\circ} \mathrm{C}\right)$ (Galdino, 2013; Rodrigues-Galdino et al., 2010), Oncorhynchus nerka $\left(10^{\circ} \mathrm{C}\right)$ (Velsen et al., $1980)$, Brevoortia tyrannus $\left(15-25^{\circ} \mathrm{C}\right)$ (Ferraro, 1980), Limanda ferruginea $\left(8-14^{\circ} \mathrm{C}\right)$ (Laurence \& Howell, 1981), Anguilla anguilla $\left(20^{\circ} \mathrm{C}\right)$ (Davidsen, 2012), Cynopoecilus melanotaenia $\left(20^{\circ} \mathrm{C}\right)$ (Arenzon et al., 2002), Coregonus clupeaformis $\left(0.5-6^{\circ} \mathrm{C}\right)$ (Price, 1940), Hexagrammos otakii $\left(12-16^{\circ} \mathrm{C}\right)(\mathrm{Hu}$ et al., 2015) and Ctenopharyngodon idella $\left(26-28^{\circ} \mathrm{C}\right)$ (Korwin-Kossakowski, 2008).

The emerald green oocytes of the P. mangurus were larger than the yellowish oocytes of the P. maculatus and other Neotropical Characiformes species such as Prochilodus scroffa (1111 $\mu \mathrm{m}$ non-hydrated) (FenerichVerani et al., 1984), Brycon insignis (1175 $\mu \mathrm{m}$ nonhydrated) (Andrade Talmelli et al., 2002) and Brycon cephalus (1001.6 $\mu \mathrm{m}$ non-hydrated) (Romagosa et al., 2001). However, P. mangurus oocytes were smaller than those observed for others Neotropical Siluriformes, such as Zungaro Jahú (1600 $\mu \mathrm{m}$ non-hydrated and 2400 $\mu \mathrm{m}$ hydrated) (Nogueira et al., 2012), R. quelen (1470 $\mu \mathrm{m}$ non-hydrated and $2640 \mu \mathrm{m}$ hydrated) and $P$. charus (1660 $\mu \mathrm{m}$ non-hydrated and $2670 \mu \mathrm{m}$ hydrated) (Vieira Sampaio \& Yoshimi, 2006).

The presented data suggest that the moderate temperature of $26^{\circ} \mathrm{C}$ is more suitable for embryo development in the five studied species, as observed similarly in previous work with the yellowtail tetra Astyanax altiparanae (Dos Santos et al., 2016). At $30^{\circ} \mathrm{C}$, decreased hatching rates and a high number of abnormal embryos were observed. Surprisingly for the marbled catfish, all embryos died when incubated at $30^{\circ} \mathrm{C}$. Most Neotropical fish species spawn during the rainy season, during which time the water temperature commonly reached a lethal limit. Therefore, this may explain the spawning behaviour of migratory fish in which rain is a main trigger to induce spawning in the reproductive season. After upstream migration, most Neotropical species wait for rain, and such behaviour synchronizes spawning of several species. Then, it is expected that rain triggers reproduction and improves egg hatchability with better water quality within an optimum range for incubation. In addition, synchronized spawning may improve survival for all fish species, including for carnivore species that have better food availability.

Only $4^{\circ} \mathrm{C}$ separates the optimal incubation temperature $\left(26^{\circ} \mathrm{C}\right)$ from the temperature at which all $P$. mangurus embryos die $\left(30^{\circ} \mathrm{C}\right)$ and this situation shows that the successful reproduction of fish species can be hampered by global warming (Ficke et al.,
2007), leading to a decline in the populations of several species. Such evidence was observed in our study due to the increased embryo mortality and larval abnormality in P. maculatus when incubated at $30^{\circ} \mathrm{C}$. Similar results was also evidenced for others Neotropical fish such as A. altiparanae (Dos Santos et al., 2016), Brycon amazonicus (da Silva et al., 2017) and $R$. quelen (Rodrigues-Galdino et al., 2010).

The establishment of incubation temperatures is interesting for application in studies involving germ cell transplantation. For blastomere transplantation, which involves embryo-to-embryo transplantation, both donor and host species must be at the blastula stage (Yamaha et al., 1998). However, development of donor and host embryos may identify a specific temperature for incubation and a specific velocity of development. Although synchronizing both embryos to the blastula stage is challenging, temperature may be easily employed to manipulate embryo development. The marbled catfish P. mangurus and the spotted catfish $P$. maculatus are an interesting model for blastomere transplantation. However, based in these results, the blastula period is very short in both species, limiting the transplantation period to a few minutes. For instance, hatching in both Neotropical catfishes in this study took place within 11 to $28 \mathrm{~h}$ post-fertilization, although other transplanted species reported in the literature have longer hatching periods, e.g. medaka Oryzias latipes (10 days post-fertilization) (Shinomiya et al., 2003; Iwamatsu, 2004), loach Misgurnus anguillicaudatus (48 h) (Fujimoto et al., 2006), zebrafish (48 h) (Kimmel et al., 1995; Lin et al., 1992) and also in salmonids in which the embryonic development takes place after several weeks (Velsen et al., 1980; Takeuchi et al., 2001; Takeuchi et al., 2003; Winckler-Sosinski et al., 2005; Okutsu et al., 2007). As seen above, most germ cell transplantations have been performed in cold water species, in which the transplantation period is longer. In Neotropical species, the presented data suggest that the transplantation strategy should be different than that for cold water species, due to a shorter transplantation period. Thus, a lower number of transplants per each egg batch will be produced in Neotropical species, suggesting that an increased number of egg batches is then required to produce an adequate number of transplanted embryos.

The success of transplantation and subsequent production of germline chimera for surrogate propagation depends on the phylogenetic relationship between donor and host species, in which related species may increase the success of germline transmission (Yamaha et al., 2007). For the spotted catfish P. maculatus, this is interesting because several species of catfish are considered endangered in the Neotropical region (Machado et al., 2008). Siluriformes are considered to be the largest group in the Neotropical region, suggesting 
that this species may become an interesting model fish for surrogate propagation with subsequent utilization in both academic and aquaculture purposes.

In conclusion, the present study verified the effect of temperature in the embryonic development of two Neotropical catfishes. This exercise is useful for embryo transplantation in Siluriformes because endangered catfish species can be used as donors of PGCs, and a common catfish species can be used as a host. This is strategic for this species and also applicable for other endangered or aquacultured catfish from the Neotropical region.

\section{Acknowledgements}

The authors would like to thank the Institudo de Biociências (IBB) of Universidade Estadual Paulista (UNESP), Botucatu, São Paulo, Brazil, in addition to the Laboratório de Biotecnologia de peixes and CEPTA/ICMBio, Pirassununga, Brazil. We would also like to thank Michael James Stablein of the University of Illinois Urbana-Champaign for his translation services and review of this work.

\section{Financial support}

The author express his gratitude to the AES Tietê for financial support.

\section{Ethical standards}

The experiments were conducted in accordance with the Ethics Committee for the Use of Laboratory Animals of the National Center for Research Conservation of Aquatic Biodiversity (CEUA/CEPTA; \#010/2015). The fish were collected in natural environments using the sampling licence according to Brazilian law (Sisbio \#55725-1).

\section{References}

Andrade Talmelli, E., Kavamoto, E. \& Narahara, M. (2002). Fenerich-Verani, Reprodução induzida da piabanha, Brycon insignis, mantida em cativeiro. Rev. Brás. Zootec. 31, 80311.

Arenzon, A., Lemos, C. \& Bohrer, M. (2002). The influence of temperature on the embryonic development of the annual fish Cynopoecilus melanotaenia (Cyprinodontiformes, Rivulidae). Brazil. J. Biol. 62, 743-7.

Brasil (2016). Sumário executivo do Livro vermelho da fauna brasileira ameaçada de extinção. Brasília, 75 pp.

Bressan, P.M., Kierulff, M.C.M. \& Sugieda, A.M. (2009). Fauna ameaçada de extinção no Estado de São Paulo. São Paulo:
Fundação Parque Zoológico de São Paulo, Secretaria do Meio Ambiente.

Comabella, Y., Hurtado, A., Canabal, J. \& García-Galano, T. (2014). Effect of temperature on hatching and growth of Cuban gar (Atractosteus tristoechus) larvae. Ecosistemas y Recursos Agropecuarios 1, 19-32.

da Silva, R.C., dos Santos, M.P., Senhorini, J.A., Paes, M.d.C.F., Valentin, F.N., Fujimoto, T., do Nascimento, N.F., Yasui, G.S. \& Nakaghi, L.S.O. (2017). The effect of temperature on the initial development of Brycon amazonicus Spix \& Agassiz, 1829 as tool for micromanipulation of embryos. Zygote 25, 637-51.

Davidsen, M. (2012). The effect of incubation temperature on embryonic development and muscle growth in yolksac larvae of the European eel (Anguilla anguilla L., 1758). Master thesis: Institutt for biologi. https://brage.bibsys. no/xmlui/handle/11250/245075

do Nascimento, N.F., Pereira-Santos, M., Piva, L.H., Manzini, B., Fujimoto, T., Senhorini, J.A., Yasui, G.S. \& Nakaghi, L.S.O. (2017). Growth, fatty acid composition, and reproductive parameters of diploid and triploid yellowtail tetra Astyanax altiparanae. Aquaculture 471, 163-71.

Dos Santos, M.P, Yasui, G.S., Xavier, P.L., de Macedo Adamov, N.S., do Nascimento, N.F., Fujimoto, T., Senhorini, J.A. \& Nakaghi, L.S. (2016). Morphology of gametes, post-fertilization events and the effect of temperature on the embryonic development of Astyanax altiparanae (Teleostei, Characidae). Zygote 24, 795-807.

Fenerich-Verani, N., Godinho, H.M. \& Narahara, M.Y. (1984). The size composition of the eggs of curimbatá, Prochilodus scrofa Steindachner 1881, induced to spawn with human chorionic gonadotropin (HCG). Aquaculture 42, 37-41.

Ferraro, S.P. (1980). Embryonic development of Atlantic menhaden, Brevoortia tyrannus, and a fish embryo age estimation method. Fish. Bull. 77, 943-9.

Ficke, A.D., Myrick, C.A. \& Hansen, L.J. (2007). Potential impacts of global climate change on freshwater fisheries. Rev. Fish Biol. Fish. 17, 581-613.

Froese, R. \& Pauly, D. (2015). FishBase. World Wide Web Electronic Publication. www.fishbase.org

Fujimoto, T., Kataoka, T., Sakao, S., Saito, T., Yamaha, E. \& Arai, K. (2006). Developmental stages and germ cell lineage of the loach (Misgurnus anguillicaudatus). Zool. Sci. 23, 977-89.

Galdino, A.M.R. (2013). Plasticidade do desenvolvimento muscular e da expressão temporal de fatores reguladores miogênicos durante os estádios iniciais de Rhamdia quelen incubados em diferentes temperaturas. https: / / educapes. capes.gov.br/handle/1884/30598

Galves, W., Shibatta, O.A. \& Jerep, F.C. (2009). Estudos sobre diversidade de peixes da bacia do alto rio Paraná: uma revisão histórica. Semina: Ciências Biológicas e da Saúde 30, 141-54.

Godinho, H.P. \& Godinho, A.L. (2003). Águas, peixes e pescadores do São Francisco das Minas Gerais, PUC Minas, Belo Horizonte.

Hu, F., Pan, L., Gao, F., Jian, Y., Wang, X., Li, L., Zhang, S. \& Guo, W. (2015). Effect of temperature on incubation period and hatching success of fat greenling (Hexagrammos otakii Jordan \& Starks) eggs. Aquacult. Res. 48, DOI: 10.1111 /are. 12853 
Iwamatsu, T. (2004). Stages of normal development in the medaka Oryzias latipes. Mech. Dev. 121, 605-18.

Jordaan, A. (2002). The effect of temperature on the development, growth and survival of Atlantic cod (Gadus morhua) during early life-histories. Master Thesis: The University of Maine. https:/ / digitalcommons.library.umaine.edu/etd/ 141/

Kimmel, C.B., Ballard, W.W., Kimmel, S.R., Ullmann, B. \& Schilling, T.F. (1995). Stages of embryonic-development of the zebrafish. Dev. Dynam. 203, 253-310.

Korwin-Kossakowski, M. (2008). The influence of temperature during the embryonic period on larval growth and development in carp, Cyprinus carpio L., and grass carp, Ctenopharyngodon idella (Val.): theoretical and practical aspects. Arch. Polish Fish. 16, 231-314.

Lahnsteiner, F., Kletzl, M. \& Weismann, T. (2012). The effect of temperature on embryonic and yolk-sac larval development in the burbot Lota. J. Fish Biol. 81, 977-86.

Laurence, G.C. \& Howell, W.H. (1981). Embryology and influence of temperature and salinity on early development and survival of yellowtail flounder Limanda ferruginea. Mar. Ecol. Prog. Ser. 6, 11-8.

Lin, S., Long, W., Chen, J. \& Hopkins, N. (1992). Production of germ-line chimeras in zebrafish by cell transplants from genetically pigmented to albino embryos. Proc. Natl. Acad. Sci. USA 89, 4519-23.

Machado, A.B. M., Drummond, G.M. \& Paglia, A.P. (2008). Livro vermelho da fauna brasileira ameaçada de extinção, MMA; Fundação Biodiversitas.

Nogueira, L.B., Azevedo, P.G., Canelhas, M.R., Bedore, A.G., Lopes, J.M. \& Godinho, H.P. (2012). Induced spawning and early ontogeny in hatchery-reared catfish Zungaro jahu (Siluriformes: Pimelodidae). Neotrop. Ichthyol. 10, 89-98.

Okutsu, T., Shikina, S., Kanno, M., Takeuchi, Y. \& Yoshizaki, G. (2007). Production of trout offspring from triploid salmon parents. Science 317, 1517.

Pepin, P. (1991). Effect of temperature and size on development, mortality, and survival rates of the pelagic early life history stages of marine fish. Can. J. Fish. Aqua. Sci. 48, 50318.

Piferrer, F., Beaumont, A., Falguiere, J.-C., Flajshans, M., Haffray, P. \& Colombo, L. (2009). Polyploid fish and shellfish: production, biology and applications to aquaculture for performance improvement and genetic containment. Aquaculture 293, 125-56.

Price, J.W. (1940). Time-temperature relations in the incubation of the whitefish, Coregonus clupeaformis (Mitchill). J. Gen. Physiol. 23, 449-68.
Rodrigues-Galdino, A.M., Maiolino, C.V., Forgati, M., Donatti, L., Mikos, J.D., Carneiro, P.C.F. \& Rios, F.S.A. (2010). Development of the neotropical catfish Rhamdia quelen (Siluriformes, Heptapteridae) incubated in different temperature regimes. Zygote 18, 131.

Romagosa, E., Narahara, M. Y., Borella, M.I. \& FenerichVerani, N. (2001). Seleção e caracterização de fêmeas de matrinxã, Brycon cephalus, induzidas a reprodução. Boletim do Instituto de Pesca 27, 139-47.

São Paulo (2014). Decreto No. 60.133, De 7 De Fevereiro De 2014.

Shinomiya, A., Shibata, N., Sakaizumi, M. \& Hamaguchi, S. (2003). Sex reversal of genetic females (XX) induced by the transplantation of XY somatic cells in the medaka, Oryzias latipes. Int. J. Dev. Biol. 46, 711-7.

Takeuchi, Y., Yoshizaki, G. \& Takeuchi, T. (2001). Production of germ-line chimeras in rainbow trout by blastomere transplantation. Mol. Reprod. Dev. 59, 380-9.

Takeuchi, Y., Yoshizaki, G. \& Takeuchi, T. (2003). Generation of live fry from intraperitoneally transplanted primordial germ cells in rainbow trout. Biol. Reprod. 69, 1142-9.

Velsen, F.J., Bernard, F., McKinnell, S. \& Jamieson, G. (1980). Embryonic Development in Eggs of Sockeye Salmon, Oncorhynchus nerka. Canadian Department of Fisheries and Oceans.

Vieira Sampaio, E. \& Yoshimi, S. (2006). Biologia reprodutiva e desova induzida de duas espécies de bagres (Osteichthyes: Siluriformes) da bacia do rio São Francisco. Acta Scientiarum. Biol. Sci. 28, DOI: 10.4025/actascibiolsci.v28i3.227

Winckler-Sosinski, L., Schwarzbold, A. \& Schulz, U. (2005). Survival of rainbow trout Oncorhynchus mykiss Walbaum, 1792 (Salmoniformes-Salmonidae) eggs in an altitude stream in southern Brazil. Acta Limnol. Bras. 17, 465-72.

Yamaha, E., Mizuno, T., Hasebe, Y., Takeda, H. \& Yamazaki, F. (1998). Dorsal specification in blastoderm at the blastula stage in the goldfish, Carassius auratus. Dev. Growth Diff. 40, 267-75.

Yamaha, E., Saito, T., Goto-Kazeto, R. \& Arai, K. (2007). Developmental biotechnology for aquaculture, with special reference to surrogate production in teleost fishes. J. Sea Res. 58, 8-22.

Yasui, G., Fujimoto, T., Sakao, S., Yamaha, E. \& Arai, K. (2011). Production of loach (Misgurnus anguillicaudatus) germ-line chimera using transplantation of primordial germ cells isolated from cryopreserved blastomeres. J. Anim. Sci. 89, 2380-8. 